\title{
EFFECTS OF HEAT INPUT ON THE MECHANICAL AND METALLURGICAL CHARACTERISTICS OF TIG WELDED INCOLOY 800HT JOINTS
}

\begin{abstract}
This study focuses on the effect of heat input on the quality characteristics of tungsten inert arc gas welded incoloy $800 \mathrm{HT}$ joints using inconel-82 filler wire. Butt welding was done on specimens with four different heat inputs by varying the process parameters like welding current and speed. The result indicated that higher heat input levels has led to the formation of coarser grain structure, reduced mechanical properties and sensitization issues on the weldments. The formation of titanium nitrides provided resistance to fracture and increased the tensile strength of the joints at high temperatures. Further aging was done on the welded sample at a temperature of $750^{\circ} \mathrm{C}$ for 500 hours and the metallographic result showed formation of carbides along the grain boundaries in a chain of discrete and globular form which increased the hardness of the material. The formation of spinel $\mathrm{NiCr}_{2} \mathrm{O}_{4} \operatorname{provided}$ oxidation resistance to the material during elevated temperature service.
\end{abstract}

Keywords: Incoloy 800HT; corrosion; aging; sensitization; heat input

\section{Introduction}

Alloy $800 \mathrm{HT}$ is an austenitic iron-nickel-chromium alloy with controlled levels of titanium, silicon, carbon, manganese and aluminium. This alloy which is one of the prominent materials for fourth generation nuclear power plant can exhibit appreciable strength, good resistance to corrosion and oxidation in high temperature environment. The high nickel content improves the resistance of alloys to cyclic oxidation, promotes a more adherent oxide layer and increases metallurgical stability and creep strength [1]. This alloy finds applications in areas like industrial heating equipments, power generation, hydrocarbon processing industry, heat exchangers, etc. Incoloy $800 \mathrm{HT}$ have their chemical composition within the limits of incoloy $800 \mathrm{H}$. Incoloy $800 \mathrm{H}$ derives its strength mainly from gamma prime $\left(\gamma^{\prime}\right)$, an intermetallic compound that enhances the strength found in other kinds of iron-nickel-base alloys with the chemical formula $\mathrm{Ni}_{3}$ (Al,Ti). Precipitation of $\gamma^{\prime}$ contributes to high temperature strength and creep resistance of the material, with the strength increasing as $\gamma$ ' volume fraction increases. The volume fraction of $\gamma^{\prime}$ in iron-nickel-base alloys is usually less than $25 \%[2,3]$. The higher carbon content and coarser grain size provide $800 \mathrm{H}$ with greater high-temperature strength [4]. Titanium is added to incoloy $800 \mathrm{H}$ to act as a carbide- and nitride-former, thereby encouraging the precipitation of titanium nitrides and titanium carbides. At temperatures between $700^{\circ} \mathrm{C}$ and $800^{\circ} \mathrm{C}$, both $\mathrm{M}_{23} \mathrm{C}_{6}$ and TiC are commonly present. Although TiC is more thermodynamically stable at these temperatures, the kinetics frequently favored the formation of $\mathrm{M}_{23} \mathrm{C}_{6}$ [5]. Tungsten inert arc gas welding (TIG) uses a tungsten electrode protected by an inert gas like helium or argon to shield the molten weld pool and red hot filler wire from atmospheric contaminants. This process can be used for joining a number of common metals such as steel, magnesium and aluminium of thickness 1-6 mm in almost all positions [6]. The performance of the welded structures is usually limited by failure commencement within the heat affected zone (HAZ) of the base metal, particularly inside the coarse-grain area of the HAZ next to to the weld metal. During welding, the weld thermal cycle produces differently featured HAZ and weld zone (WZ) microstructures and the different phase microstructures correspond to different mechanical properties. If the microstructural changes in the HAZ are not controlled as a result of improper selection of welding variables, undesirable metallurgical structures may be produced, consequence of which may lead to poor joint quality of the weld and eventual failure of material in service [7]. Therefore, selecting suitable heat input is one of the primary means by which acceptable weld properties can be achieved. Mohamed Abu Aesh [8] reported that increasing welding rate and speed in TIG welding directly affects the width of HAZ. R. Kayano et al. [9] investigated the susceptibility to solidification cracking by varying the amount of nickel content in inconel 706 and reported that lower solidification temperature is the cause for solidification cracking while increasing the nickel content. Yu

\footnotetext{
NATIONAL INSTITUTE OF TECHNOLOGY, DEPARTMENT OF PRODUCTION ENGINEERING, TIRUCHIRAPPALLI-620015, TAMILNADU, INDIA

Corresponding author: psathiya @ nitt.edu
} 
Cao et al. [10] studied the effects of annealing time and prestrain during the post deformation recrystallization at $1000^{\circ} \mathrm{C}$ on incoloy $800 \mathrm{H}$ grain boundary character and concluded that $\sum 3$ regeneration was the main mechanism for the increase in $\Sigma 3^{n}$ boundaries. P.Sathiya et al. [11] optimized the friction welding process parameters of incoloy $800 \mathrm{H}$ joints using artificial neural network and concluded that the low heating pressure, upsetting time and high upsetting pressure, heating time are required to obtain sound quality joint. Xizang Chen. et al. [12] investigated the stress distribution of alloy $800 \mathrm{H}$ joints made by TIG welding process and concluded that the residual stress reduced gradually as the distance from weld seam increases. Arun Kumar et al. [13] studied the effect of different activating flux on A-TIG welding processes of alloy $800 \mathrm{H}$ and reported that sensitization was caused because of higher heat input provided by the $\mathrm{SiO}_{2}$ flux. Purmohamed et al. [14] modeled multi pass TIG process using FEA for incoloy $800 \mathrm{H}$ and reported that wider weld zone and higher HAZ peak temperature were observed when increasing the heat input. From the above literatures, it was found that only a few works have been carried out in TIG welding of incoloy $800 \mathrm{H}$. So this study focuses on the influences of heat input on the metallurgical and mechanical characteristics of TIG welded Incoloy $800 \mathrm{HT}$ joints. The tensile strength, hardness, toughness, high-temperature tensile strength at $750^{\circ} \mathrm{C}$, hot corrosion properties, fractography and ageing properties were analyzed and the results are discussed.

\section{Materials and Methods}

Incoloy $800 \mathrm{HT}$ plates of dimension $150 \times 100 \times 4 \mathrm{~mm}$ were butt welded using Lincoln TIG machine, with polarity direct current electrode negative [DCEN]. The composition of the chemical elements present in alloy $800 \mathrm{HT}$ and N82 filler wire is given in Table 1. The input process parameters used for welding were the welding current; voltage and welding speed are listed in Table 2. Argon was used as the shielding gas at the flow rate of $15 \mathrm{lpm}$. The single $\mathrm{V}$ groove joint was prepared with an included angle of $70^{\circ}$, root face of $0.8 \mathrm{~mm}$ and root gap of $1.2 \mathrm{~mm}$. Four passes were made by maintaining the interpass temperature to complete weld.The standard method of metallographic sample preparation was adopted and the section perpendicular to the welding direction is taken as object. The emery sheets of various grades were used to polish the specimens and then etched with $15 \mathrm{ml} \mathrm{HCL}+10 \mathrm{ml} \mathrm{HAC}+10 \mathrm{ml} \mathrm{HNO}_{3}$ to observe the structure of the weld joints. Because of the tiny indentation of microhardness test, the samples' surface roughness will affect the test results directly. So the samples' hardness should be tested as the samples soon as pass through polishing and etching. Microhardness tester (TMVS-1S) was used to determine microhardness at traverse cross- section of the welded joints (WZ, HAZ, BM) at different locations, loaded with $500 \mathrm{~g}$ for $15 \mathrm{~s}$ during testing. The tensile test at room temperature and high-temperature tensile test at $750^{\circ} \mathrm{C}$ were carried out according to ASME SEC IX standard. The Charpy test specimens were prepared according to the
ASTM E-23 standard. Pendulum impact testing machine at room temperature was used to determine the impact toughness of the joints. The SEM with EDS analysis was done using Carl Zeiss $\sigma$ version machine in high vacuum mode. The fracture surface of the impact and tensile tested specimen were analyzed through scanning electron microscope (SEM). The X-Ray diffraction (XRD) results were taken using D/Max ULTIMA III machine in continuous mode. The cyclic hot corrosion test was performed using molten salt of $40 \% \mathrm{Na}_{2} \mathrm{SO}_{4}+\mathrm{V}_{2} \mathrm{O}_{5}$. A uniform coating of the molten salt was applied $\left(3-5 \mathrm{mg} / \mathrm{cm}^{2}\right)$ on the sample of dimension $12 \times 10 \times 4 \mathrm{~mm}$ which was preheated to $250^{\circ} \mathrm{C}$. One hour of heating at $750^{\circ} \mathrm{C}$ was done on a tubular furnace followed by cooling at room temperature for $20 \mathrm{~min}$. After each cycle the weights of the sample was measured with the help of a electronic balance and the changes in weight were recorded.

TABLE 1

Chemical composition of the base metal and filler wire.

\begin{tabular}{|c|c|c|}
\hline Elements & $\begin{array}{c}\text { INCOLOY 800H } \\
\text { (Wt\%) }\end{array}$ & $\begin{array}{c}\text { INCONEL 82 } \\
\text { (Wt\%) }\end{array}$ \\
\hline $\mathrm{C}$ & 0.065 & 0.10 \\
\hline $\mathrm{Mn}$ & 0.688 & 2.5 \\
\hline $\mathrm{S}$ & $<0.010$ & 0.0015 \\
\hline $\mathrm{Si}$ & 0.094 & 0.485 \\
\hline $\mathrm{Cu}$ & 0.091 & 0.30 \\
\hline $\mathrm{Cr}$ & 20.79 & 19.94 \\
\hline $\mathrm{Fe}$ & 46.60 & 2.69 \\
\hline $\mathrm{Al}$ & 0.277 & - \\
\hline $\mathrm{Ti}$ & 0.280 & 0.7 \\
\hline $\mathrm{Ni}$ & 30.65 & 71.24 \\
\hline $\mathrm{Nb}$ & 0.01 & 2.00 \\
\hline $\mathrm{P}$ & 0.008 & 0.03 \\
\hline $\mathrm{Co}$ & 0.08 & - \\
\hline $\mathrm{N}$ & 0.013 & - \\
\hline
\end{tabular}

TABLE 2

Process parameter and heat input

\begin{tabular}{|c|c|c|c|c|}
\hline \hline $\begin{array}{c}\text { Experiment } \\
\text { number }\end{array}$ & $\begin{array}{c}\text { Welding current } \\
\text { (A) }\end{array}$ & $\begin{array}{c}\text { Voltage } \\
\text { (V) }\end{array}$ & $\begin{array}{c}\text { Welding speed } \\
\text { (mm/s) }\end{array}$ & $\begin{array}{c}\text { Heat input } \\
\text { (J/mm/s) }\end{array}$ \\
\hline 1 & 90 & 10 & 1.2 & 750 \\
\hline 2 & 110 & 12 & 1.4 & 942 \\
\hline 3 & 130 & 14 & 1.6 & 1137 \\
\hline 4 & 150 & 16 & 1.8 & 1333 \\
\hline
\end{tabular}

\section{Result and discussion}

\subsection{Microstructural analysis}

Fig. 1 shows the microstructure of incoloy $800 \mathrm{HT}$ as received in mill and annealed condition.

The microstructure consisted of a solid solution matrix in which some grains were delineated by precipitate particle at the boundaries and by twining lines. The spheroidal particles along the grain boundaries represent titanium carbide whereas the 


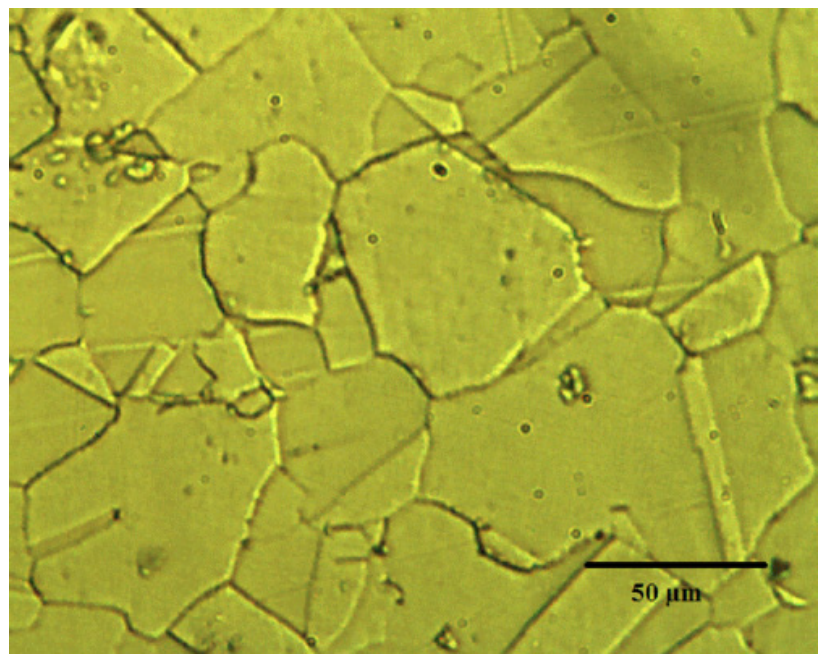

Fig. 1. Microstructure of incoloy $800 \mathrm{HT}$

cuboidal precipitates present in the matrix of austenite represent the titanium nitrate which was formed from the melt during solidification [15]. The microstructure of the weld region for experiment 2 and 4 is shown in( Fig. 2a,b).
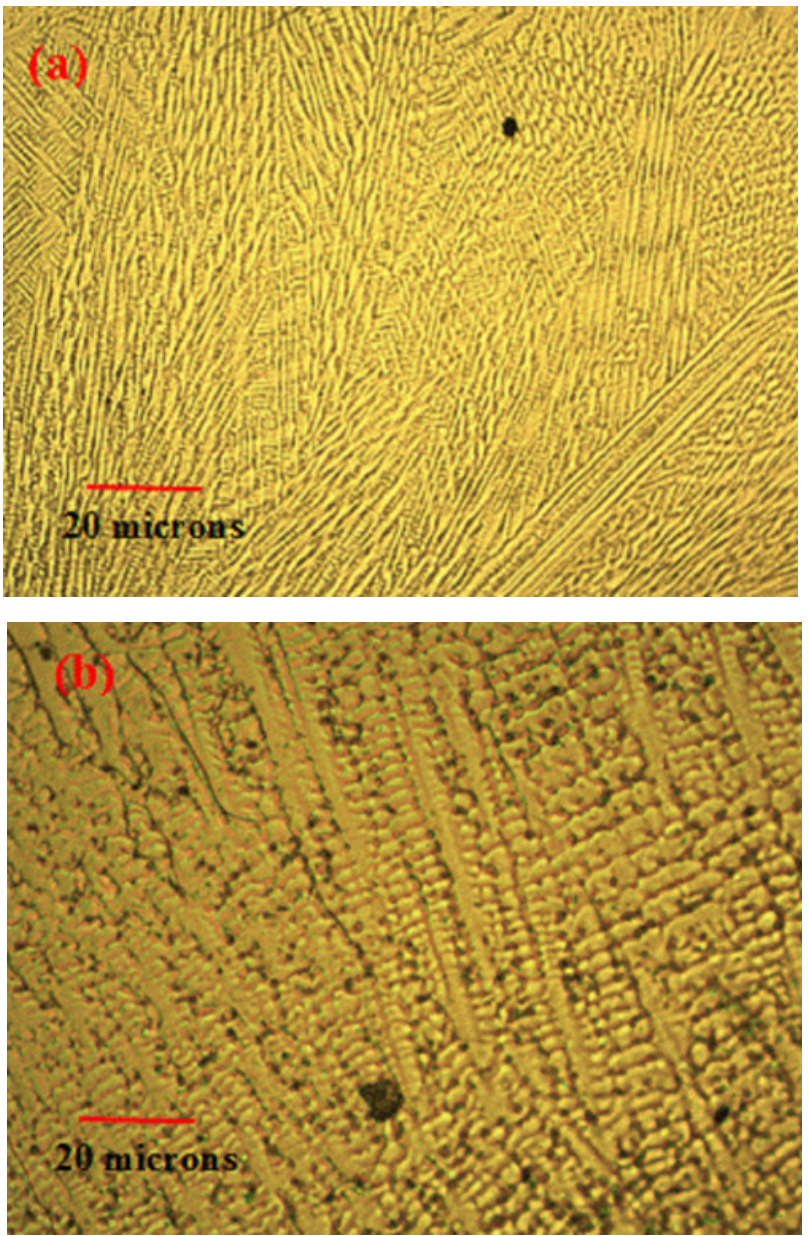

Fig. 2. Microstructure of the weld zone (a) experiment 2 (b) experiment 4

The microstructure for experiment 2 shows fully austenitic structure with fine cellular and equiaxed grains all over the weld regions whereas the weld zone microstructure of experiment 4

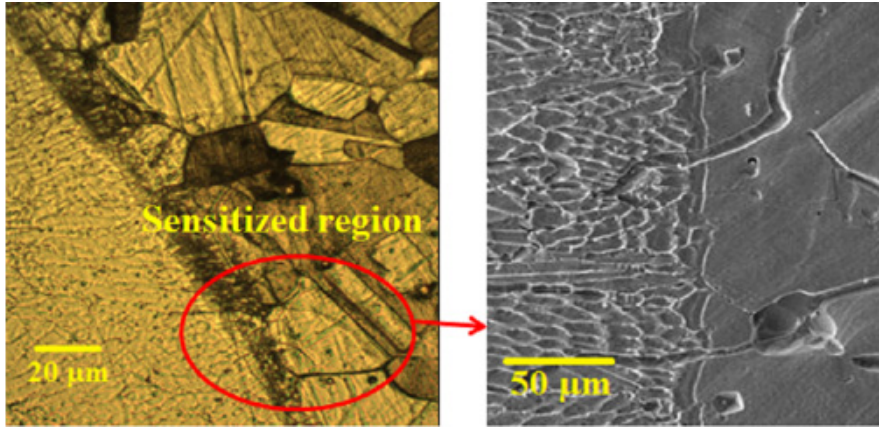

Fig. 3. microstructure of sensitized zone (experiment 4)

showed harder dendritic structres which were more prone to cracking. The higher heat input during welding might be the cause for the formation of harder dendritic structure. The structure of the weld zone clearly explains why there was a variation in mechanical strength for experiment 2 and 4.

Fig. 3 shows the sensitization issue that has occurred in the HAZ for experiment 4 due to the high heat input concentration. Sensitization is a breakdown in corrosion resistance associated with the precipitation of chromium-rich carbides such as $\mathrm{M}_{23} \mathrm{C}_{6}$ and $\mathrm{M}_{7} \mathrm{C}_{3}$ along grain boundaries. Interstitial carbon can diffuse rapidly whereas chromium diffuses much more slowly. This results in a chromium depleted zone adjacent to grain boundaries, caused by the formation of chromium carbides which remove chromium from solution. The depletion of chromium places the grain boundary region in a "sensitized" state, with the depleted region anodic with respect to the bulk material, which results in accelerated corrosion along the grain boundaries. Sensitization can lead to severe intergranular corrosion in situations where the alloy is exposed to an environment capable of attacking the alloy [3].

\subsection{Effect of heat input on tensile strength and hardness}

The mechanical properties of the weld joints are shown in Table 3.

TABLE 3

Mechanical properties of the welded joints

\begin{tabular}{|c|c|c|c|c|c|c|}
\hline \hline $\begin{array}{c}\text { Expe- } \\
\text { riment } \\
\text { number }\end{array}$ & $\begin{array}{c}\text { Y.S } \\
{[\mathbf{R . T}]} \\
\mathbf{( M P a )}\end{array}$ & $\begin{array}{c}\text { UTS } \\
{[\mathbf{R} . \mathbf{T}]} \\
\mathbf{( M P a )}\end{array}$ & $\begin{array}{c}\text { Y.S } \\
{\left[\mathbf{7 5 0}^{\circ} \mathbf{C}\right]} \\
\mathbf{( M P a )}\end{array}$ & $\begin{array}{c}\text { UTS } \\
{\left[\mathbf{7 5 0}^{\circ} \mathbf{C}\right]} \\
\mathbf{( M P a})\end{array}$ & $\begin{array}{c}\text { Hard- } \\
\text { ness } \\
(\mathbf{H V})\end{array}$ & $\begin{array}{c}\text { Tough- } \\
\text { ness } \\
(\mathbf{J})\end{array}$ \\
\hline 1 & 400 & 612 & 380 & 584 & 179 & 68 \\
\hline 2 & 426 & 628 & 403 & 596 & 188 & 72 \\
\hline 3 & 386 & 588 & 360 & 565 & 168 & 60 \\
\hline 4 & 394 & 568 & 337 & 544 & 163 & 54 \\
\hline
\end{tabular}

The tensile strength of Incoloy HT joints increased with decrease in heat input which is clear from Table 3. It can be seen that during low heat input conditions, width of HAZ is very small around the fusion zone which varies when changes to higher heat input. During higher heat input carbides precipitates a lot along 
the grain boundaries leading to sensitized zone around grain boundaries which helps in grain coarsening of HAZ and decrease in hardness around that area and finally the specimen undergoes brittle fracture under proper loading conditions. The weld metal microstructural details in terms of cell arrangement and dendritic spacing, shows that high ductility and strength was obtained at lower heat input which was due to the less dendrite sizes and smaller inters dendritic spacing in the fusion zone. Comparatively the joints with higher heat input possessed larger dendrite sizes. It can be noted that the material at $750^{\circ} \mathrm{C}$ also had appreciable load bearing capacity with small loss of strength as compared to the room temperature tensile test results. Further the fracture surface morphology was analysed to find the possible reasons for the retained strength at high temperature-because most of the steel loses its strength at high temperatures drastically.

\subsection{Fractography analysis}

Fig. 4a,b shows the typical fractograph(s) of the impact tested specimen.
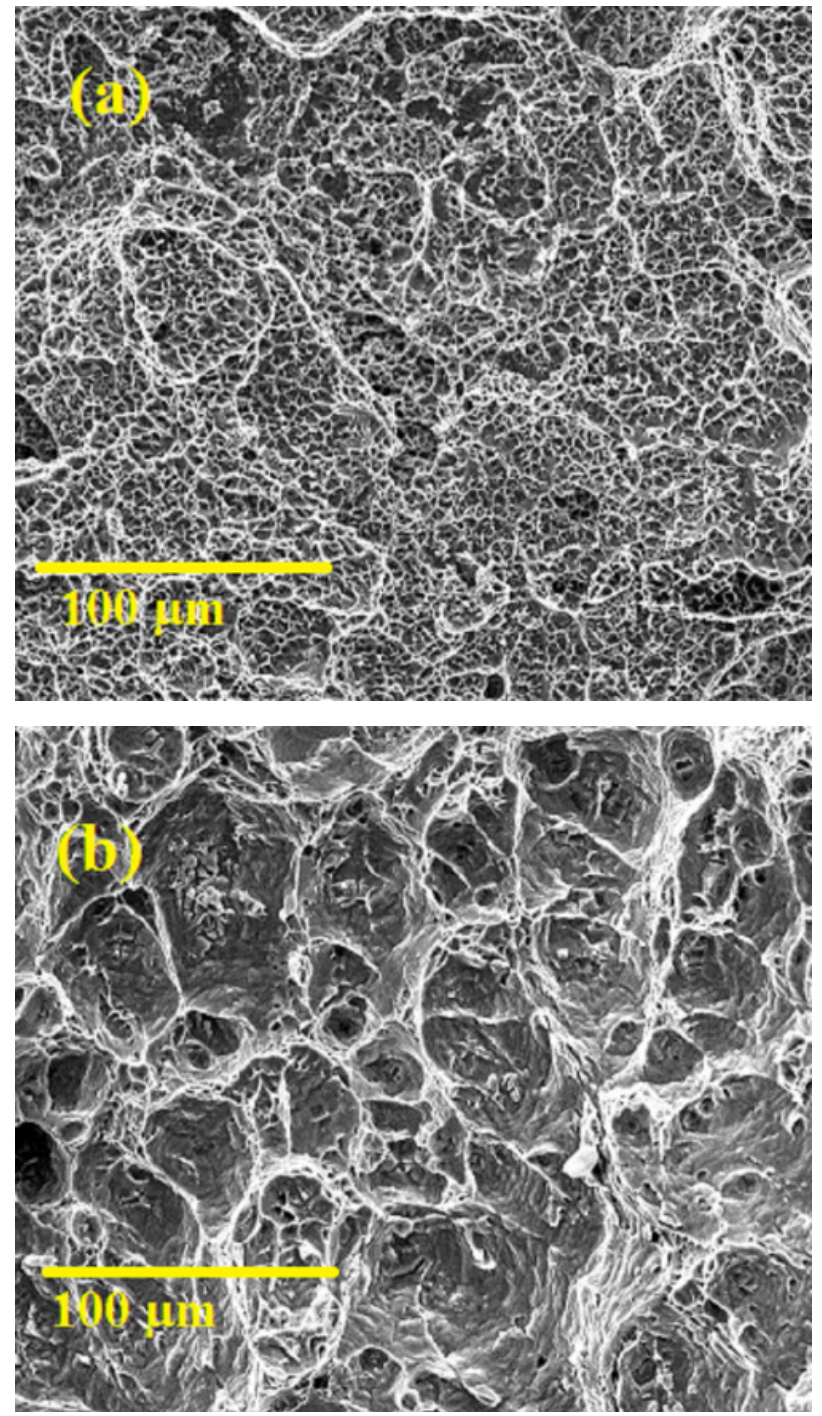

Fig. 4. fractography of the impact tested specimen (a) experiment 2 (b) experiment 4
The impact tested specimens were analyzed on the fractured surface by SEM to investigate the type of fracture that has occurred. Fig. 4a corresponds to the fractographic images taken for experiment 2 and it showed deep and wide dimples which revealed ductile fracture mode whereas Fig. $4 \mathrm{~b}$ which corresponds to experiment 4 showed mostly cleavages which revealed brittle mode of fracture.

The Fig. 5a and 5b show the fractograph(s) of the fracture surface of the tensile and high-temperature tensile tested sample for experiment 2 with better mechanical properties as compared to other joints. Both fractograph(s) shows deep and narrow dimples which corresponded to the ductile mode of fracture. Also the high-temperature tensile test fractograph(s) (Fig. 5b) showed titanium nitride on the fracture surface. These particles do not dissolve under high temperature conditions and also provide coherent strength to the matrix and improves the material fracture toughness [16]. From the results it is clear that the alloy $800 \mathrm{H}$ could withstand high temperatures without losing its strength. As compared to room temperature tensile properties, the high temperature tensile result also showed good strength with only a small amount of loss in strength.
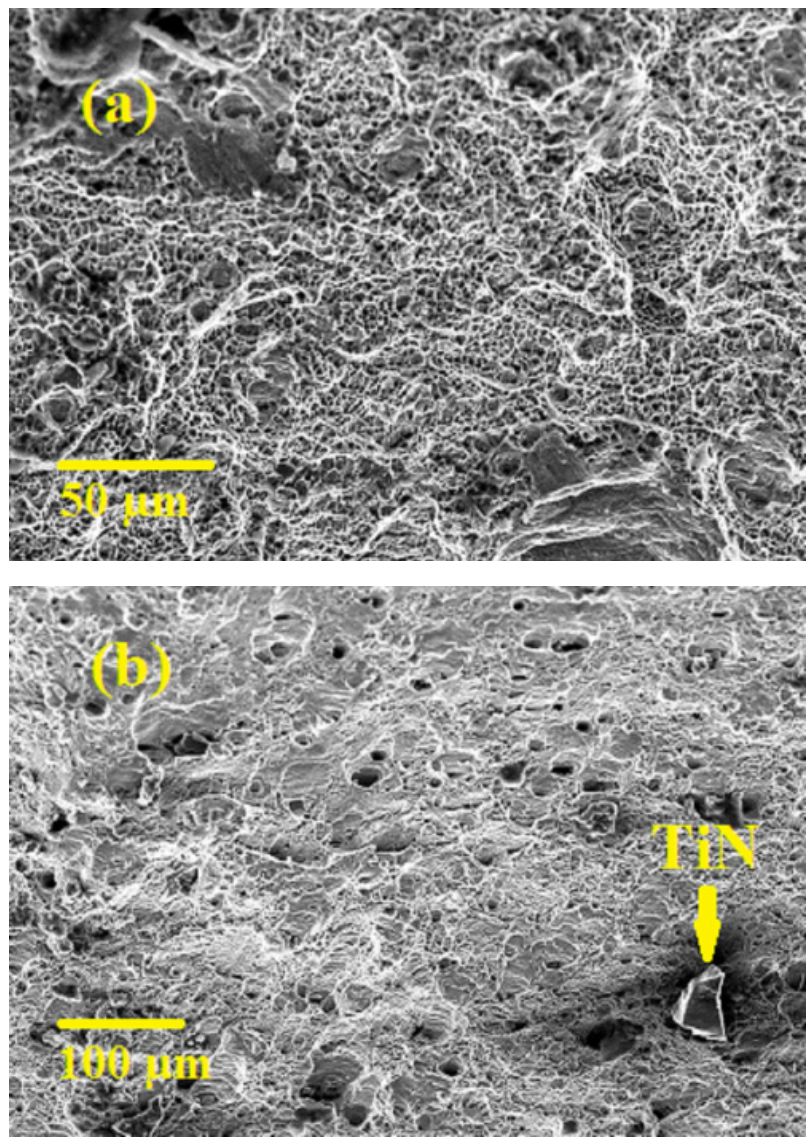

Fig. 5. (a) and (b) fractography of tensile and hot tensile tested specimen (experiment 2)

\subsection{Cyclic hot corrosion behavior}

The cyclic hot corrosion test was performed for the welded specimen (experiment 2). On visual observation during the cyclic 
hot corrosion test, spalling occurred after a few initial cycles. As the cycle progressed the corroded particles formed a boat in green color with grey patches.

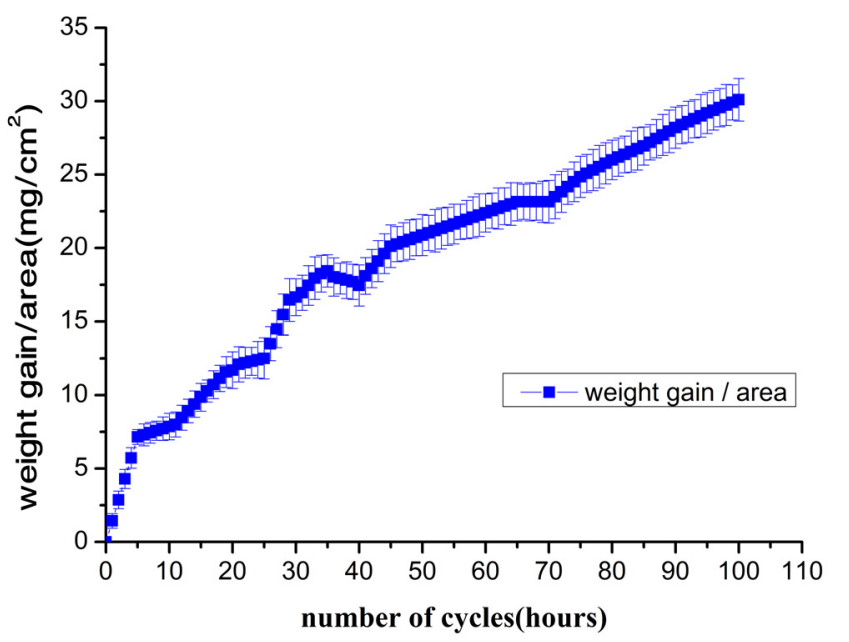

Fig. 6. Weight gain during hot corrosion analysis
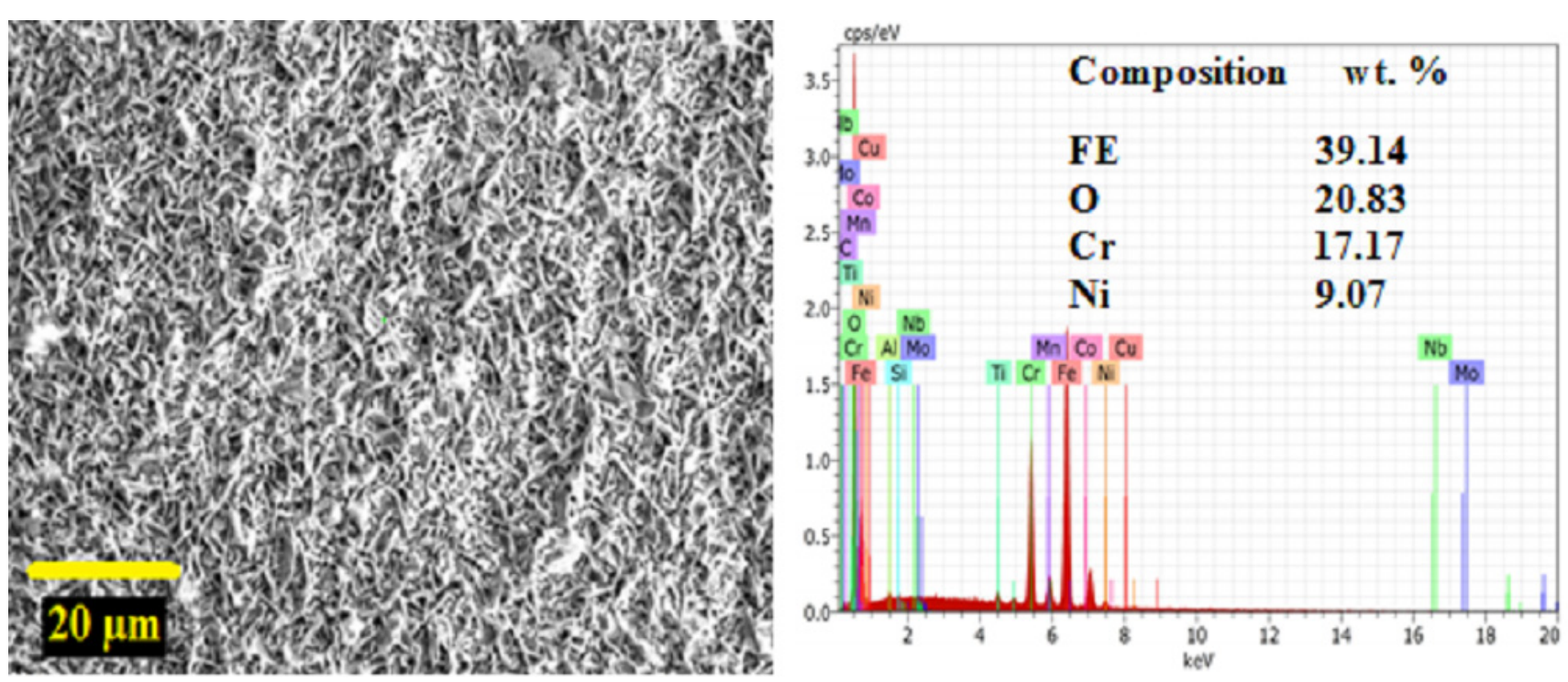

Fig. 7. SEM with EDS analysis of the scales

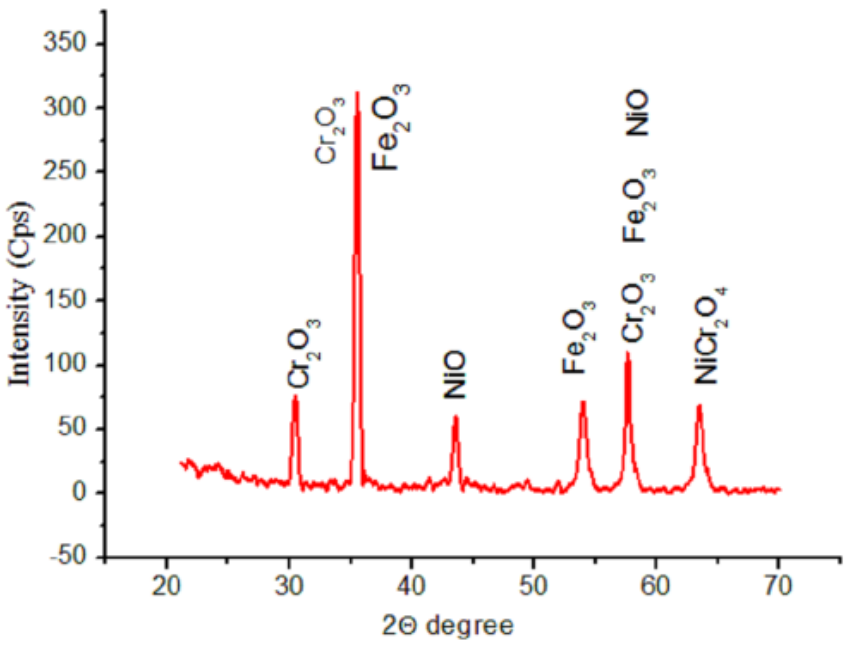

Fig. 8. XRD analysis of the scales
Fig. 6 shows the gain in weight for the sample subjected to 100 cycles for the base material and the welded area.The initial gain in weight was because of the penetration of the oxidizing particles in the open pores and rapid formation of $\mathrm{Cr}_{2} \mathrm{O}_{3}$ at the grain boundaries. After a few initial cycles the changes in weight were gradual. The SEM with EDS and XRD analysis was performed to check the scale morphology and the phases present as shown in (Figs. 7,8).

The EDS and XRD analysis were made on the scale with dense clusters developed on specimen during hot corrosion. The scale consisted mainly of $\mathrm{Fe}, \mathrm{O}, \mathrm{Cr}$ and $\mathrm{Ni}$ rich elements \& suggesting the formation of $\mathrm{Fe}_{2} \mathrm{O}_{3}, \mathrm{NiO}, \mathrm{Cr}_{2} \mathrm{O}_{3}$ and their spinel $\mathrm{NiCr}_{2} \mathrm{O}_{4} \cdot \mathrm{NiCr}_{2} \mathrm{O}_{4}$ spinel formed by the solid phase reaction in the oxide, seals $\mathrm{NiO} \& \mathrm{Cr}_{2} \mathrm{O}_{3}$ which developed oxidation resistance as the spinel phase had lower co-efficient of diffusion of the anions and cations than that of the parent oxides. The corroded specimen showed uneven protrusion formation in the entire oxidized surface along the grain boundaries and a similar protruding behavior was reported by Kamal et al [17].

\subsection{Potentio dynamic polarization analysis}

The electro chemical corrosion test for base material and weld zone (experiment 2) was carried out in electrochemical station (IVIUM) which consisted of 3 cells; calomel as reference electrode, graphite as counter electrode and the specimen as work electrode. 1 mole of $\mathrm{NaCl}$ per liter of distilled water was used as the electrolytic solution and the specimens were exposed to $1 \mathrm{~cm}^{2}$ area. The local polarization curve was plotted from $-1 \mathrm{~V}$ to $1 \mathrm{~V}$ at a scan rate of $0.5 \mathrm{mV} / \mathrm{s}$. During testing, time duration of 1 hour was given to stabilize the corrosion potential. Fig. 9 shows the polarization curves of base metal as received and the weld area. The polarization curve is plotted by varying the voltage with respect to time and the corresponding changes in current densities were obtained. As the current density increases 
the loss of electrons from the surface is more and if the current density decreases, the loss of electrons from the surface is less thus indicating better resistance to corrosion.

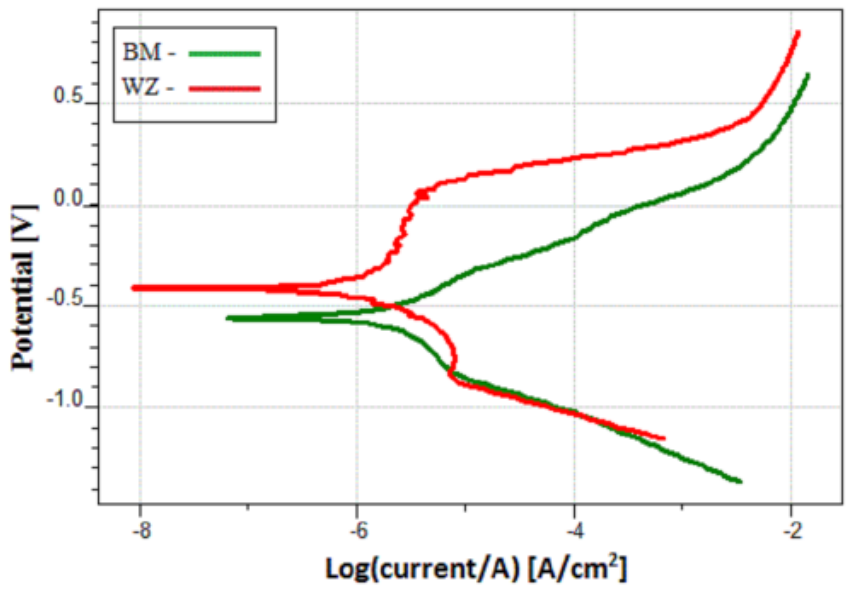

Fig. 9. Tafel plot

From Fig. 9 it is observed that the current density was minimum for the weld area and also the potential was moving towards the positive direction which indicated that the weld region have higher corrosion resistance than the base metal [18].

\subsection{Aged properties of the weld metal}

The welded specimen of experiment 2 was aged at $750^{\circ} \mathrm{C}$ for a holding time of $500 \mathrm{hrs}$. The ageing process was carried out in a automatic controlled box type muffle furnace. Figs. 10 and 11 show the aged microstructure of the WZ, HAZ and the base metal and hardness values for experiment 2. During ageing the weld metal may be softened in the initial stages of heat treatment due to recovery processes. Further heat treatment will lead to the formation of precipitates which cause increase in the hardness. For longer aging time periods, a balance occurs between recovery process and precipitation. Therefore the final result depends on any one of them that has higher rate. The maximum average hardness value observed after $500 \mathrm{hrs}$ of aging for the three weld zones, (WM, HAZ and BM) shows that the WM and HAZ zones had higher values than the base metal and $16 \%$ increase in hardness as compared. This increase of hardness value at the weld metal could be attributed to the presence of secondary phaseformed during aging. The increase of hardness value at HAZ could be attributed to the effect of thermal cycle on the microstructure variation. Comparing the hardness taken without ageing, the aged specimens had higher hardness which was due the formation of precipitates in the austenite matrix and along the grain boundaries which can be seen from Fig. 12 .

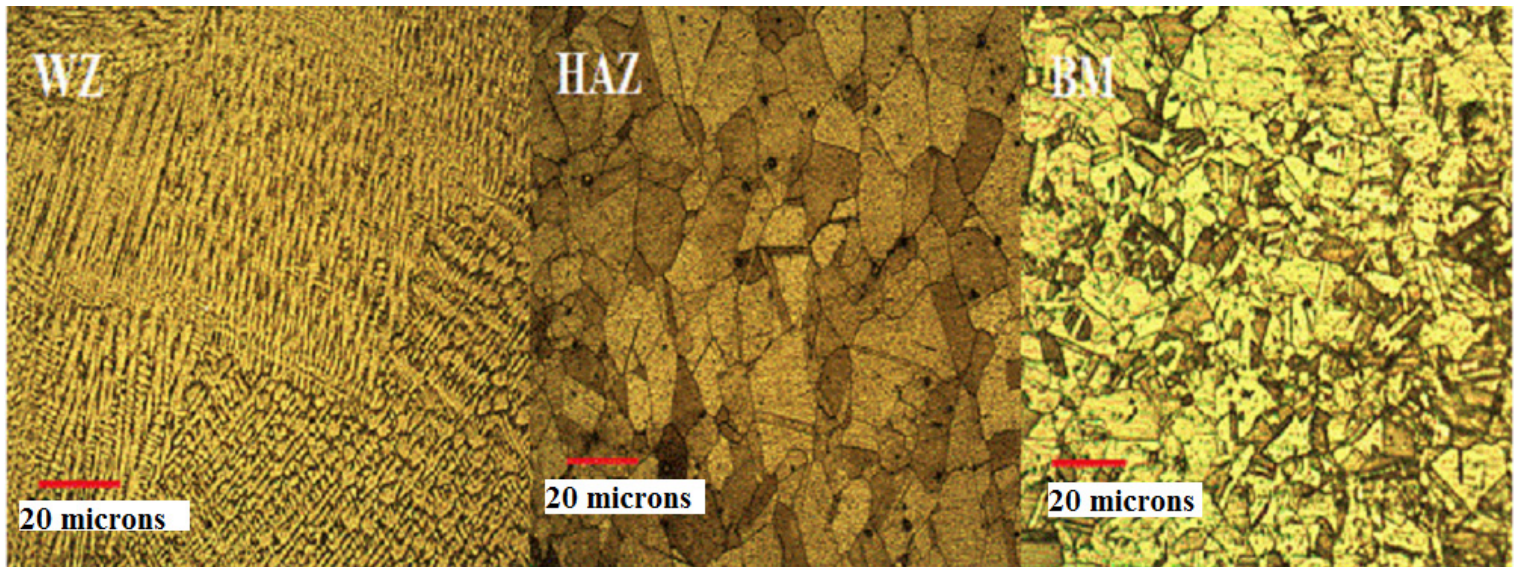

Fig. 10. Aged sample microstructure (experiment 2)

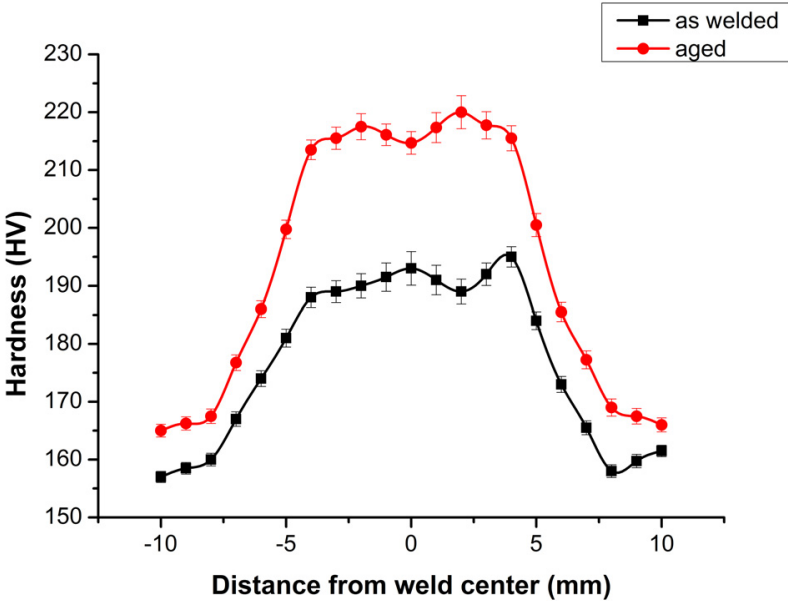

Fig. 11. Hardness of aged and in as-welded condition

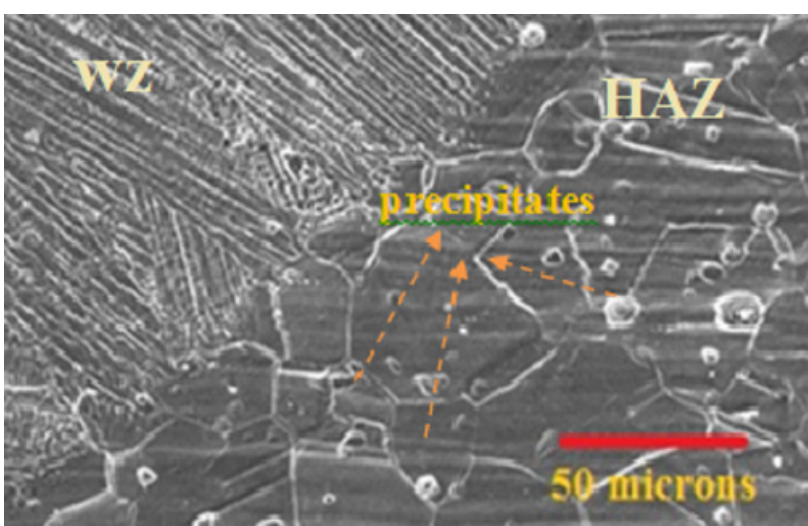

Fig. 12. SEM image of the aged sample 


\section{Conclusions}

The TIG welding was carried out on incoloy $800 \mathrm{HT}$ using inconel-82 filler wire at four different heat inputs. The mechanical properties of the weld joint decreased as the heat input increased. The difference in mechanical property was due to the different microstructure obtained. The lower heat input resulted in finer grain size which increased the mechanical properties, whereas the higher heat input led to the formation of harder dendritic structure and sensitization issue in the heat affected zone. The fractograph of the high-temperature tensile tested specimen revealed some titanium nitrides on the fracture surface which increased the fracture strength. The hot corrosion test revealed the formation of $\mathrm{NiCr}_{2} \mathrm{O}_{4}$ spinel that provides oxidation resistance to the alloys during high temperature exposure. The aged samples showed the formation of carbides along the grain boundaries and in austentite matrix which increased the hardness compared to the as welded samples.

\section{REFERENCES}

[1] H. Rahmel, J. Grabke, W. Steinkusch, Mater. Corros. 49, 221-225 (1998).

[2] J.C. Langevoort, L.J. Hanekamp, P.J. Gellings, Appl. Surf. Sci. 28, 189-203 (1987)
[3] J.R. Davis, ASM Specialty Handbook Committee-Stainless steels, ASM International, Materials Park, Ohio 1994.

[4] J.R. Davis, ASM Specialty Handbook-Heat-resistant materials, ASM International, Materials Park, Ohio 1997.

[5] A. Czyrska-Filemonowicz, J. Ennis, Nucl. Technol. 66, 149-157 (1984).

[6] Pawan Kumar, Kishor Purushottamrao Kolhe, Sashikant Janardan Morey, Chanchal Kumar Datta, Mater. Sci. Appl. 2, 251-257 (2011).

[7] K.S. Bipin, S.P. Tewarl, Int. J. Eng. Sci. 2, 1425-1432 (2010).

[8] M. Abu Aesh, Mater. Manuf. Processes. 16, 725-736 (2001).

[9] R. Kayano, T. Ishiguro, Weld. Int. 13, 430-439 (1999).

[10] Yu Cao, Hongshuang Di, Mater. Lett. 163, 24-27 (2016).

[11] K. Anand, Birendra Kumar Barik, K. Tamilmannan, P. Sathiya, JESTCH 18, 394-407 (2015).

[12] Xizhang Chen, Shu Yan Zhang, Jingjun Wang, Joe F. Kelleher, Mater. Des. 76, 26-31 (2015).

[13] Srirangan Arun Kumar, Paulraj Sathiya, Mater. Manuf. Processes. 30, 1154-1159 (2015).

[14] H. Purmohamad, A. Kermanpur, M. Shamanian, Int. J. Press. Vessels Pip. 87, 424-432 (2010).

[15] G. Sayiram, N. Arivazhagan, Mater. Charact. 102, 180-188 (2015).

[16] M. Sireesha, V. Shankar, Shaju K. Albert, S. Sundarsan, Mater. Sci. Eng. A 292, 74-82 (2000).

[17] S. Kamal, R. Jayaganthan, S. Prakash, Bull. Mater. Sci. 33, 299306 (2010).

[18] X.J. Yan, D.Z. Yang, X.P. Liu, Mater. Charact. 58, 623-628 (2007). 